This item was submitted to Loughborough's Research Repository by the author.

Items in Figshare are protected by copyright, with all rights reserved, unless otherwise indicated.

\title{
Thermoplastic composite beam structures from mixtures of recycled HDPE and rubber crumb for acoustic energy absorption
}

PLEASE CITE THE PUBLISHED VERSION

http://dx.doi.org/10.1177/0892705716681836

PUBLISHER

SAGE

VERSION

AM (Accepted Manuscript)

\section{PUBLISHER STATEMENT}

This work is made available according to the conditions of the Creative Commons Attribution-NonCommercialNoDerivatives 4.0 International (CC BY-NC-ND 4.0) licence. Full details of this licence are available at: https://creativecommons.org/licenses/by-nc-nd/4.0/

\section{LICENCE}

CC BY-NC-ND 4.0

\section{REPOSITORY RECORD}

Haworth, Barry, D. Chadwick, L. Chen, and Y.J. Ang. 2016. "Thermoplastic Composite Beam Structures from Mixtures of Recycled HDPE and Rubber Crumb for Acoustic Energy Absorption”. figshare. https://hdl.handle.net/2134/23130. 


\title{
Thermoplastic Composite Beam Structures from Mixtures of Recycled HDPE and Rubber Crumb for Acoustic Energy Absorption
}

\author{
B. Haworth ${ }^{(1)}$, D. Chadwick ${ }^{(2)}$, L. Chen ${ }^{(1)}$ and Y.J. Ang ${ }^{(1)}$
}

\begin{abstract}
The use of recycled rubber crumb in the design and production of thermoplastic-rubber composites as sound absorbers can provide solutions to noise pollution and for the recovery of post-consumer materials from both packaging and waste tyres. The work of this study is concerned with the effect of rubber crumb incorporation in high density polyethylene (HDPE) and also in HDPE glass-fibre composites on acoustic, mechanical and physical properties. Recycled HDPE compounds containing variable concentrations of cured rubber crumb particles were prepared by twin screw extrusion. Thermal analysis has revealed a significant increase in the level of crystallinity of the HDPE component by increasing the rubber content in the mixes. Standard three-point bending and notched impact test specimens were manufactured by injection moulding and large-scale beam samples were produced by compression moulding using an adhoc method that allows variation of the through-thickness elastomer content as a means of obtaining composition gradients. The flexural modulus and impact strength varied monotonically with rubber crumb concentration. A Fast Fourier Transform (FFT) technique was used to determine the acoustic performance of the beams over a wide frequency range. The graded structures produced large improvements in acoustic absorption properties in the frequency range $2-6 \mathrm{kHz}$, notably from composite beams containing $20 \%$ rubber and also in some multilayer beams with rubber concentration gradients.
\end{abstract}

\section{Keywords:}

Polymer composites; beam design; recycled rubber, recycled HDPE, injection moulding, morphology, mechanical \& acoustic properties.

(1) Department of Materials, Loughborough University, LE11 3TU, UK

(2) Testsure Technology Ltd, Uttoxeter, UK

\section{Corresponding author:}

Barry Haworth, Reader in Polymer Engineering, Department of Materials, Loughborough University, Loughborough, Leicestershire LE11 3TU, UK.

E-mail: B.Haworth@lboro.ac.uk 


\section{Introduction}

The rapid development of modern transport infrastructure is highly beneficial to society, yet causes major problems of urban community noise that is undesirable and potentially hazardous to human health and local environments. Road traffic is a significant source of noise, since the number of vehicles has increased dramatically in most countries over the past few decades but other sources such as aircraft/airport, railways and construction noise also contribute to increasing noise pollution ${ }^{1-3}$. This can be expressed in terms of the frequency and sound pressure level boundaries relative to the audible range of human hearing $^{1}$, so that solutions to the issue of noise pollution have become a major focus for future development of modern transportation systems. Solutions to these problems will undoubtedly involve innovative design with new and enhanced composite materials, such as foams and sound damping formulations, as a way of producing structures capable to act as sound absorbers for the protection of residential communities from noise pollution. Natural materials have been researched for sound absorption and noise reduction ${ }^{4-6}$, however these have been found to exhibit inadequate absorption coefficients while good soundproofing properties can only be achieved over a narrow frequency range. Murugan et al. ${ }^{7}$ have shown, on the other hand, that recycled polyolefin-based plastic waste, as well as thermoplastic composites produced from recycled materials, offers excellent potential for sound barriers. More recently, recycled rubber crumb has found a significant range of applications as a sound absorption material, for use along highways and between buildings to reduce noise in neighbouring residential areas $^{8-9}$.

The use of recycled rubber crumb for sound absorbing structures not only helps in solving existing environmental problems of traffic and other transport noise pollution, but offers also a potential solution for end-of-life tyre waste management ${ }^{8-10}$. It has been estimated that around 2.5 million tonnes of waste tyres are accumulated each year in the European Union and 3.25 million tonnes in the United States ${ }^{10-11}$. Whilst waste tyres have in the past been disposed mainly through landfill, increasing concern about the environmental protection and sustainable development (together with more stringent legislation such as the European Commission Directives: The Waste Landfill Directive 1999/31/EC and The End of Life Vehicle Directive 2000/53/EC) have led to a substantial decrease in landfilling of these products. Waste management techniques including recycling, tyre derived fuel and 'waste to energy' options are each providing acceptable alternatives to landfill ${ }^{11-13}$. More specifically, civil engineering applications for recycled crumb contribute significantly to a large proportion of the market and these solutions are expected to grow ${ }^{10,14-15}$. The good performance of recycled rubber crumb in acoustic damping and in sound absorbing properties has been reported previously. These studies have shown that improvements in acoustic damping 
capability can be obtained over a wide frequency range, owing to the high porosity caused by the dispersed particles ${ }^{8,9,11}$. The effects of adhesives and polymeric binders have also been studied ${ }^{9,13,16-17}$ while Zhou et al. $^{2}$ have developed composite sound absorbing perforated panels, combining double-layer structures of recycled rubber particles with opencell polyurethane foam. More recently, the sound insulation properties of wood/recycled tyre rubber composite panels have been investigated and it has been shown that an increase in recycled rubber crumb produced improvements in soundproofing properties ${ }^{3}$.

Studies on soundproofing properties of thermoplastic/recycled rubber crumb composite products have not been widely reported. Bearing in mind the function that some of the products are intended to serve as structural materials, it is important to also consider other physical properties and processes, notably mechanical fixing by nails or screws when substituting traditional timber products. In this respect it should be noted that the properties of the related thermoplastic composites are not only influenced by rubber crumb concentration, but may also be controlled through the addition of glass fibres in order to improve a range of mechanical properties including modulus, strength and toughness, as well as creep resistance. Previous work ${ }^{4,8,18-19}$ has provided the evidence that glass fibres can be used as sound absorbents as a means of reducing environmental noise.

In the case of composite materials and structures it should be borne in mind that the sound energy is transmitted and some is reflected from the surface. At the same time a fraction of the incident energy is also absorbed by the material as thermally dissipated energy. The energy balance can, therefore, be written $\mathrm{as}^{1,3}$ :

$$
E_{i}=E_{t}+E_{r}+E_{a}
$$

Where $E$ represents energy and the subscripts represent the various types of energy involved, i.e. $\mathrm{i}=$ incident, $\mathrm{t}=$ transmitted, $\mathrm{r}=$ reflected and $\mathrm{a}=$ absorbed.

The soundproofing performance of composite materials and structures is known to be related to frequency, component thickness, surface finish/texture and material composition, as well as to the fixing systems used in practice. Attenuation and sound absorption in materials are attributed to two main mechanisms, namely: energy dissipation caused by viscous loss through molecular motions and the additional energy dissipation caused by mechanical friction effects between constituent material/particles under the influence of the sound waves. It can be assumed, therefore, that a combination of viscoelastic behaviour of the materials within the composite structure and the incorporation of large interface areas in the design of macro-scale structures (including porous media, particles of complex shape and fibres) can offer efficient soundproofing characteristics. The 
sound absorption coefficient $(\alpha)$ is defined as the fraction of the incident sound energy absorbed $^{1,20}$, i.e.:

$$
\alpha=\frac{E_{a}}{E_{i}}
$$

Some material data listing sound absorption coefficients $(\alpha)$ and corresponding values of noise reduction coefficient (NRC) have been widely reported ${ }^{1,4,7}$. The use of rubber particles is known to be very effective in enhancing the sound absorption characteristics across a wide range of frequencies, exhibiting $\alpha$ values between 0.2 and 0.56 within a frequency range 250 to $2000 \mathrm{~Hz}$. (Note the $\alpha$ value is simply the fraction of incident energy absorbed by the material or structure; equation 2).

Whilst the overall dimensions of large scale structures assume an obvious high level of importance, it has to be borne in mind that sound absorption properties are affected by the microstructural characteristics of absorbers, as these exert considerable influence on the three main fundamental parameters, such as flow resistivity, porosity and tortuosity ${ }^{1,8,21-23}$. For systems containing rubber crumb, the interfacial friction between matrix and rubber particles can also cause damping of incident energy ${ }^{1,21}$, which is enhanced by the geometric irregularity of the particles and the resulting interfacial porosity ${ }^{3}$. While increasing rubber content in the composite may cause significant reduction in modulus, reducing the size of rubber particles has been found to be beneficial ${ }^{9}$ and that the best performance is obtained with smaller particle size $(<0.35 \mathrm{~mm})$, due to the high sound path length associated with high tortuosity around the particles and increased interfacial friction ${ }^{2}$. It has also been suggested that as rubber content reaches a certain level, the aggregation of smaller rubber particles may reduce soundproofing performance ${ }^{3}$, possibly because of the low energy dissipation by interfacial friction between rubber particles.

Previous investigations have shown that a deterioration of mechanical properties takes place when ground rubber tyre powders are incorporated into recycled polyethylene, which has been attributed to the weak interfacial adhesion between the rubber and PE matrix and is not significantly influenced by the mean particle size (between 380 and $1200 \mu \mathrm{m}$ ) or surface roughness of the particles ${ }^{26}$. The present study examines primarily the effect of recycled rubber crumb at different concentration levels on the physical, mechanical and acoustic properties of recycled HDPE-based thermoplastic composite beams, which includes the effect of rubber concentration gradients from the surface of multilayer composite products, as well as the use of two different arrangements of continuous glass fibres as reinforcing components. 


\section{Experimental}

\section{Materials}

The materials used to manufacture the composite beams were

(i) A recycled grade of high density polyethylene (HDPE) derived from postconsumer bottle waste supplied by Thermoplastic Composites (UK) Limited (nominal melt flow index $2.6 \mathrm{dg} \mathrm{min}^{-1}$ )

(ii) A recycled vulcanised rubber powder (CS0420-0000), supplied by Rubber Crumb Limited.

(iii) Continuous E-glass fibres in the form of glass ribbon and glass rod coated with a proprietary functional bonding agent, supplied by Thermoplastic Composites (UK) Limited.

\section{Processing Techniques}

An APV MP20/30 twin screw compounding unit (screw diameter 30mm, length to diameter L/D ratio 30:1) fitted with gravimetric feeders, a 2-strand die and downstream pelletising system was used to compound recycled HDPE and rubber crumb to produce a series of composite materials with rubber concentration varying between 5 and $20 \%$ by weight. Process conditions were as follows: screw speed $210 \mathrm{rpm}$, mass output $5 \mathrm{~kg} \mathrm{hr}^{-1}$ and a maximum die temperature of $210{ }^{\circ} \mathrm{C}$. The control HDPE sample (post-consumer recycled HDPE) was also 'compounded' to achieve an identical thermal history to the other compounds. Injection moulding of rectangular-section notched / un-notched specimens was used for all HDPE/rubber crumb compounds using a Negri-Bossi NB62-tonnes injection moulding machine (maximum melt temperature $210{ }^{\circ} \mathrm{C}$; mould tool temperature $30{ }^{\circ} \mathrm{C}$ ). Unnotched beams were produced for three-point bending tests, whilst the sharp notched beams were used for Izod impact tests: nominal beam dimensions were $60 \mathrm{~mm}$ (length), $12 \mathrm{~mm}$ (width) and $6 \mathrm{~mm}$ in depth; the notch length was $3 \mathrm{~mm}$ with a tip radius of $0.25 \mathrm{~mm}$. A 50-tonnes hydraulic press was used to prepare the HDPE/rubber crumb beams at a temperature of $200{ }^{\circ} \mathrm{C}$ under a constant pressure of 10 tonnes. The mould used to prepare the beams has dimensions $320 \mathrm{~mm}$ (length), $60 \mathrm{~mm}$ (width) and $28 \mathrm{~mm}$ (depth).The formulations of the materials used for compression moulding are shown in Table I, and the configurations of the glass ribbons and glass rods in the mould are shown in Figure 1. (Two pieces of glass ribbons formed a layer in the mould, while three glass rods, aligned by two shorter glass rods with an epoxy adhesive, were also placed as a distinct layer. 
The particle morphology of rubber crumb was analysed using a Cambridge Stereoscan 360 Scanning Electron Microscope (SEM), using an acceleration voltage of $20 \mathrm{kV}$. In addition, energy-dispersive X-ray (EDX) spectroscopy was employed for elemental analysis and chemical characterisation, to identify specific types of additives. The Coulter LS-130 (Fraunhofer) model was used to study the particle size distribution (PSD) of the rubber crumbs in a propanol suspension produced with the aid of a magnetic stirrer. BET Analysis (Tristar-3000 analyser, Micromeritics) was used to obtain information about the surface area and porosity of the rubber crumb, using $1 \mathrm{~g}$ samples and a 40-minute experimental time.

Differential Scanning Calorimetry (DSC) was used to analyse the endothermic melting and crystallisation behaviour of the HDPE/rubber crumb compounds with the aid of a TA Instruments DSC, using a heating rate of $10{ }^{\circ} \mathrm{C} \mathrm{min}^{-1}$ with an isotherm (5 minutes at 200 ${ }^{\circ} \mathrm{C}$ ) followed by a thermal cycle at $20^{\circ} \mathrm{C} \mathrm{min}^{-1}$, using a sample weight of $10-11 \mathrm{mg}$.

\section{Mechanical Properties}

Flexural tests were performed at room temperature according to ASTM D790-10, using a Lloyd Instruments LR50K tensometer. The specimens used were respectively un-notched injection moulded samples and compression moulded composite beams. The injection moulded specimens were simply supported beams with span length of $50 \mathrm{~mm}$ and loaded at the opposite midpoint with a crosshead speed of $60 \mathrm{~mm} \mathrm{~min}^{-1}$. The data were analysed to estimate flexural stress, strain and the secant flexural modulus at $1 \%$ strain. Compression moulded beams were tested under the same conditions using a span length of $200 \mathrm{~mm}$, a $50 \mathrm{kN}$ load cell and a clamp separation rate set at $1 \mathrm{~mm} \mathrm{~min}^{-1}$. Izod impact testing was carried out at room temperature using a Ray-Ran pendulum impact unit according to ASTM D256-10 (fixed vertical cantilever beams and struck by a pendulum with hammer weight $1.796 \mathrm{~kg}$, impact velocity $\left.3.5 \mathrm{~m} \mathrm{~s}^{-1}\right)$.

\section{Morphology}

Samples were analysed using different microscopy techniques in order to assess the degree of mixing and the microstructure of the compounded HDPE/rubber crumb composites. Notched injection moulded samples were cryogenically fractured then sputter coated and analysed by SEM as described above. The X-ray backscatter facility was used to identify the elastomer phase and EDX spectroscopy was used for elemental analysis.

\section{Determination of Acoustic Properties}

Acoustic tests for compression moulded beams were carried out at Thermoplastic Composites (UK) Ltd. Sharp edge pulses caused a piezo-crystal transmitter (placed at one 
point of the beam) to oscillate, which produces 'white' noise containing a wide band of frequencies. A receiver was placed at the other end of the beam, situated $105 \mathrm{~mm}$ from the transmitter. The energy transmitted through the sample was detected by the receiver, amplified and a software routine was used to capture time domain signals and to convert the voltage-time plot to a Fast Fourier Transform (FFT) spectrum, for amplitude-frequency analysis. From the acoustic tests, the noise signals produced from voltage-time plots are transformed to amplitude-frequency spectra to demonstrate the acoustic performance of compression moulded beam samples. Sound frequencies in the range 2-6 kHz usually correspond to human hearing and the observed transmission peaks are mainly situated within this region. Good acoustic performance is exemplified by low measured amplitudes, indicating reduced sound transmission. Hence, the areas under the amplitude-frequency curves (in the 2-6 kHz range) are calculated to estimate the transmitted sound intensity in the frequency range of interest. Overall, the reason for using this method is that it is more realistic to the envisaged industrial applications for which sound absorption, rather than reflection of the incident waves, is the target.

\section{Results and Discussion}

\section{Characterisation of raw materials and compounds}

SEM micrographs of 'as-supplied' recycled rubber crumb particles (Figure 2) have verified that the particle size distribution lies within the range $100-600 \mu \mathrm{m}$, with a mean particle size of $340 \mu \mathrm{m}$. The rubber particles have an irregular geometry originating from the preparation technique and are well segregated. Some thread-like fibrous materials (diameter approximately $20 \mu \mathrm{m}$ ) can also be observed, due to the presence of reinforcing fibres from waste automotive tyres. The SEM-EDX spectrum taken from a small area of rubber crumb surface confirms that the recycled rubber particle surfaces contain elements of carbon, oxygen, sulphur, zinc and silicon; the weight and atomic content of these elements are presented in Table II. Sulphur is commonly used as a vulcanising agent for the crosslinking of rubber compounds and zinc oxide is an activator. Silicon content can be attributed to the use of silicone rubber in the tread part of low energy tyres, and/or from silica particles.

The Coulter LS-130 makes use of laser light diffraction with a patented Polarisation Intensity Differential Scattering (PIDS) technology ${ }^{25}$. Particle size distribution (PSD) curves are produced (see Figure 3 ) and together with the size distribution parameters provide an indication of packing and flow characteristics of particles within a continuous medium. The data show a very uniform particle size distribution, with a range between 168 to $504 \mu \mathrm{m}$ with a mean particle size of $327 \mu \mathrm{m}$ (Table III). The absence of secondary peaks in the distribution curve denotes the absence of significant levels of particle agglomeration in the 
supplied particulate materials. The BET surface area of the rubber crumb sample was found to be $0.215 \mathrm{~m}^{2} \mathrm{~g}^{-1}$ with adsorption / desorption pore diameters of 10.7 and $7.3 \mathrm{~nm}$ (respectively). In other studies, the porosity of rubber recyclate has been shown to provide an effective sound absorption mechanism, provided that the size of the aggregates and the binder content are carefully controlled and the component thickness is adjusted to the frequency range of interest ${ }^{9}$.

The thermal analysis data for rubber/HDPE compounds obtained from cooling and second heating scans are shown in Figure 4. Re-crystallisation and melting temperatures shown are taken from the peak values rather than onset data; the areas under the endothermic peaks correspond to melting enthalpy from which the HDPE crystallinity is estimated. In order to erase the previous processing thermal history, the second (re-heating) scans were used to compare the melting characteristics of the materials. The crystallinity of the HDPE component $\left(\chi_{c}\right)$ is obtained from ${ }^{27}$ :

$$
\chi_{c}=\frac{\Delta H_{m}}{\Delta H_{100} .\left(1-w_{r}\right)} \times 100 \%
$$

$\Delta \mathrm{H}_{\mathrm{m}}$ is the experimental enthalpy of melting, $\Delta \mathrm{H}_{100}$ is the enthalpy of melting for $100 \%$ crystalline HDPE (taken as $295 \mathrm{~J} \mathrm{~g}^{-1}$ ) 28 and $\mathrm{w}_{\mathrm{r}}$ is the weight fraction of rubber.

Re-crystallisation and melting temperatures are respectively 116 and $137^{\circ} \mathrm{C}$, which remains invariant for all compounds produced, confirming the anticipated lack of miscibility with the amorphous rubber particles (Figure 4). The crystallinity in HDPE products usually lies between 80 and $85 \%$, depending on chain structure, molecular weight and thermal history ${ }^{28}$. In this case, the observed crystallinity of recycled HDPE has a lower value $(71.6 \%)$, presumably owing to the mixture of polymer types, grades and additives arising from the recycling process. Chain branching can also occur in PE when subjected to re-processing, which would also be expected to contribute to the observed reduction in crystallinity. The crystallinity of the HDPE component is found to increase slightly with the rubber content over the entire concentration range, reaching a maximum at around $75 \%$. This observation is unlikely to be associated with heterogeneous nucleation effects since the onset and peak temperatures on cooling are unaffected (Figure 4a). It is proposed that the in-cavity cooling rates decrease when rubber crumb is added due to reduced thermal diffusivity, allowing greater opportunity for crystallisation within the HDPE phase.

\section{Flexural Properties of HDPE / rubber crumb compositions}

Flexural stress $\left(\sigma_{f}\right)$, strain $\left(\varepsilon_{f}\right)$ and modulus (secant at $1 \%$ strain, as derived from the raw data) were obtained using elastic beam theory, which are calculated using the equations 


$$
\sigma_{f}=\frac{3 P L}{2 b d^{2}} \quad \text { and } \quad \varepsilon_{f}=\frac{6 D d}{L^{2}}
$$

where $P$ is the maximum load on the load-deflection curve, $L$ is the length of the support span, $D$ is the deflection of the centre of the beam of width $b$ and depth $d$. The flexural stress-strain graphs are shown in Figure 5. Deformation resistance at low strain is important for beam design and, therefore, tests were terminated at around 17\% nominal strain, beyond the region in which gross plastic deformation was first observed.

The variation of mechanical properties with rubber concentration is summarised in Figure 6. Flexural stress and modulus decrease monotonically with increasing the rubber crumb concentration, whilst the corresponding flexural strain exhibits the opposite trend. Experimental variability was comparatively low in all cases, confirming the consistency of the formulations and manufacturing techniques. Overall, the $20 \%$ rubber-filled HDPE compound exhibits $28 \%$ and $36 \%$ reductions in flexural stress and secant modulus, respectively, whereas the flexural strain exhibits a $33 \%$ increase, when compared to the control sample. These data are consistent with other research reported on similar compositions of rigid thermoplastics modified by cross-linked elastomers. Due to the permanent network structure of the elastomer phase, short range interfacial compatibility with the HDPE cannot occur since the cross-linked rubber molecules cannot flow and diffuse through the interface with the thermoplastic matrix, owing to both the mentioned thermodynamic immiscibility and the network structure, resulting in distinct two-phase structures with the possible formation of voids ${ }^{29}$.

\section{Izod impact properties}

Impact measurements were used as a guide to mechanical performance under impulse loading situations. Standard impact tests only measure the specific fracture energy $\left(U_{k}\right)$ which corresponds to the fracture energy per unit cross-section area and is generally known as 'impact strength'. Although $U_{k}$ is not a fundamental property, the data can be used as a first order approximation for comparisons. The data obtained are shown in Figure 7 and demonstrate that all elastomer-filled systems experience an approximate $40 \%$ reduction in specific fracture energy, relative to the neat recycled HDPE. The reason for the large drop in notched Izod impact strength is rooted in the loss of ductility of the HDPE matrix resulting from the triaxiality of the stress field at the notch tip and the lack of interfacial adhesion with the rubber particles, which create preformed crack paths through the matrix.

\section{Fractography}


Micrographs of the cryogenic fractured surfaces of injection moulded specimens were examined by SEM and the related X-ray backscatter technique, as shown in Figures 8-9. The SEM images of the specimen surfaces allow adequate detection of the particulate elastomer phase, whilst the backscattered electron imaging technique provides a good contrast between rubber crumb particles and HDPE owing to the presence of heavy elements in the vulcanised rubber, such as sulphur and zinc, which backscatter electrons more strongly than the comparatively light atoms in PE and, therefore, produce brighter images $^{30}$. The trend with rubber concentration in the mixtures is clear. These observations are confirmed in the SEM-EDX analysis of the original rubber crumb (Figure 9b), which shows a similar chemical composition as those described earlier (Table II).

\section{Mechanical Properties of Compression Moulded Beams}

\section{Effect of rubber content and concentration gradients in HDPE}

The influence of recycled rubber crumb content and concentration gradient on the mechanical behaviour of the products examined is illustrated in Figures 10-11 (see also Table I). Although the flexural modulus of the composite beams decreases monotonically with rubber crumb concentration (Figure 10), the data in Figure 11 confirm that influence of the concentration gradient is more complex. For example, sample 6 with a high rubber crumb loading (20\%) in the outer layers and a lower concentration near the centre exhibits an intermediate flexural modulus (496 MPa), which is similar to the value for the uniform beam containing $10 \%$ rubber. Sample 14 with a low rubber concentration on the outside layer (5\%) exhibits enhanced flexural properties in comparison with sample 12 , which also has a symmetrical distribution of rubber with a maximum of $20 \%$ in the centre layers and $10 \%$ rubber in the external surface layer. This demonstrates the importance of material composition close to the external surface of the specimens under flexural loads, where the state of stresses is dominated by the tensile stress component. The rubber concentration near the centre of the beam is clearly shown to be less influential on the flexural behaviour of the composites. These data therefore provide opportunity for optimising both mechanical and acoustic properties in composite beam design.

\section{Effects of glass reinforcement}

While the mechanical properties of thermoplastic composites are enhanced by the incorporation of high aspect ratio glass reinforcement, for the case of HDPE systems, the surface energy discrepancy between the non-polar polymer and glass fibres gives rise to poor interfacial bonding, which prevents the achievement of high levels of reinforcement. The results of this study show that incorporating two layers of glass ribbons provides only a 
modest increase in flexural modulus (in the region of 10\%) due to the occurrence of debonding within the glass ribbons (Figure 12) and, also to the presence of voids. Consistent increases in flexural modulus with glass rod reinforcement diameter (and hence concentration / volume fraction) is evident from the data in Figure 13. For example, the use of $8.7 \mathrm{~mm}$ diameter rods (sample 10) has resulted in a $140 \%$ enhancement in the stiffness of the beam. Further improvements are expected if the interfacial adhesion between HDPE and glass is enhanced and if the formation of internal voids is prevented during manufacture (Figure 12b). The effects of rubber content, concentration gradients, glass ribbon layers, glass rod diameter and rubber/glass composite beams are summarised in Figure 13 (categorised as beam sample groups 1-5, respectively).

\section{Acoustic properties}

The noise signals in voltage-time plots from the acoustic tests are transformed to amplitudefrequency spectra, in order to demonstrate the acoustic performance of compression moulded beam samples. The target is to achieve low measured amplitudes, indicating reduced sound transmission through the structures, so that the areas under the amplitudefrequency curves indicate the transmitted sound intensity in the frequency range of interest $(2-6 \mathrm{kHz})$.

This measurement technique determines sound absorption characteristics specifically, as relevant to many potential applications for sound barriers in the construction sector. For structural applications there may be earth, stone or concrete on the rear face of the structures, so that preventing reflection and causing absorption are important mechanisms. In a through transmission test a material that was highly reflective would exhibit little sound transmission but would reflect large amounts of noise back into the environment, so that sound transmission data is less useful for the envisaged applications. The macro mechanical resonance of the structures is at a much lower frequency than 2-6 $\mathrm{kHz}$ and is not the method of attenuation which was sought in this research; rather we are seeking, through sequential partial reflection, to 'trap' the sound energy inside the barrier and cause energy loss, hence the measurement technique chosen. As well as preventing reflection of the incident wave this also prevents transmission so that both are achieved simultaneously.

The raw data obtained for the acoustic measurements are summarised in Table IV and some examples of the graphical output from acoustic tests are shown in Figures 14-16.

Sound intensity, or 'sound power density, is a vector which can be estimated from the sound power relative to the area over which energy transmission is taking place, hence units are typically in $\mathrm{W} \mathrm{m}^{2}$. However, it is more relevant to express data as a sound intensity level $\left(I_{L}\right)$ which is defined relative to a reference level by: 


$$
I_{L}=10 \log \left(\frac{I}{I_{0}}\right)
$$

Where:

$\mathrm{I}=$ sound intensity $\left(\mathrm{W} \mathrm{m}^{-2}\right)$ and $\mathrm{I}_{0}$ is the reference sound intensity $\left(1 \times 10^{-12} \mathrm{~W} \mathrm{~m}^{-2}=0 \mathrm{~dB}\right)$.

The output data in Figures 14-16 are shown in $\mathrm{dB}$ and this can be related sound intensity level using this approach. For example, a measurement detection of $40 \mathrm{~dB}$ is a sound amplification of $10^{4}$, therefore equivalent to $10^{-8} \mathrm{~W} \mathrm{~m}$.

\section{Effect of Rubber Crumb Concentration}

The data in Table IV (specimens 1-5) show that the transmitted sound intensities for rubber concentrations up to $15 \%$ exhibit little difference, relative to the recycled HDPE reference, while the transmitted sound intensity for the $20 \%$ rubber significantly decreases (Figure 14 ac). This observation is significant and is also indicative of the potential to exploit the enhanced acoustic performance by incorporating concentration gradients of the elastomer phase in the HDPE. Rubber crumb has adequate air flow resistivity, porosity and especially high tortuosity, which lengthens sound transmission routes and hence absorbs more sound energy $^{8}$. Furthermore, Zhao et al. $^{3}$ indicated that carbon black in rubber crumb causes increasing diffraction and dispersion of transmitted sound waves.

\section{Effect of Rubber Crumb Concentration Gradient}

While the concentration gradient in the beams was intended to be symmetrical about the centre axis, the manufacturing techniques used has not made it possible to achieve precise control of the through thickness concentration of rubber crumb. Instead, the samples are likely to consist of blurred concentration gradients, without distinct boundaries between the layers. Some interesting variations in acoustic data have been achieved on various samples in Table IV which can be exemplified by the following observations: for beams with low rubber concentrations on the incident surface (samples 12 and 14), the absorbed sound intensity is not improved. Sample 15, on the other hand, offers the best performance relative to the overall amount of rubber crumb. It should be noted that this sample has an asymmetrical rubber concentration gradient. The measured differences in acoustic properties between samples 12 and 13, which differ only with respect to the thickness of the centre layer containing $20 \%$ rubber crumb, demonstrate the importance of component dimensions to control attenuation effects (Figure 15). 
The advantage of multilayer sound absorbs over monolayer beams is that a larger proportion of sound waves can be refracted from the surface of each layer and can also be absorbed within each layer, as reported elsewhere ${ }^{31}$.

\section{Effect of Glass Ribbon / Rod Reinforcements}

The sound absorption of glass fibres is mainly attributed to sound energy attenuation by scattering from the fibres and by vibrations within the individual fibres ${ }^{1}$. Furthermore, fibrous materials often possess large flow resistivity and porosity (for example, spacing between individual fibres, within rovings) that are also beneficial for acoustic absorption ${ }^{18,22}$. Thus, as observed in Table IV, glass rod reinforced composites (samples 8 to 10) and glass ribbon reinforced beams (sample 7) offer some improvement in soundproofing performance relative to the reference HDPE (probably attributed to sound reflection from the macro-scale reinforcement), but the output data do not compare favourably with the optimum performance of sample 5 (HDPE $+20 \%$ rubber beam, Figure 14c). Glass ribbon reinforced HDPE, without the addition of rubber (samples 16,17 ) has produced poor sound absorption characteristics (Figure 16b). It has been suggested that soundproof properties are enhanced when an effective interface zone is formed, since sound energy is dissipated by reflecting and refracting mechanisms in the continuous composite interface ${ }^{3}$. The present study shows that if rubber crumb is added to HDPE containing glass fibres, the soundproof performance of the resulting more complex composite structure is significantly improved (sample 11).

Although the experimental research has been carried out on an appropriate macroscopic scale, the specimen size is clearly much smaller than typical sound barrier structures used in industrial applications. The research outcomes provide the basis to suggest that scale-up towards industry-scale structures is feasible and it is demonstrated that this can be achieved using post-consumer recycled polymers, thus ensuring a positive contribution towards the increased use of sustainable materials.

\section{Conclusion}

Post-consumer recycled materials, including HDPE (from a high molecular weight bottle grade source) and recycled rubber crumb (from mechanically-ground tyres), have been compounded successfully to produce composite materials containing up to $20 \%$ elastomer. An analysis based upon SEM / EDX has been used to determine the main elemental compositions, such as sulphur and zinc oxide, which are commonly used in the vulcanisation of rubber compounds. The presence of silicon, on the other hand, can be ascribed to the use in the tread part of low energy tyres containing silica reinforcement. The particle size 
distribution of elastomer crumb is uniform with a mean equivalent diameter around 320$340 \mu \mathrm{m}$. The thermal behaviour, such as re-crystallisation and melting temperatures of HDPE/rubber compounds are all very similar; however the HDPE crystallinity increases slightly with the addition of rubber crumb, attributed to the decrease in cooling rate of the HDPE as a result of the reduction in the overall thermal diffusivity of the composite. Injection moulded specimens and compression moulded beams exhibit similar trends, showing a monotonic decrease in flexural modulus with increasing rubber crumb concentration. Compression moulded beam samples exhibit inferior mechanical performance compared with injection moulded samples due to the low pressure nature of the process which prevents adequate compaction being achieved.

Acoustic properties have been analysed in terms of sound absorption in the frequency range 2-6 $\mathrm{kHz}$ and have been found to be enhanced by the incorporation of the recycled crosslinked elastomer. Optimum acoustic damping behaviour is observed for the sample containing $20 \%$ rubber crumb. Other moulded beams with variable rubber concentration gradients also show enhanced acoustic absorption, demonstrating the viability for manufacturing scaled-up components. Composite beams containing glass fibres are also found to contribute to the absorption of acoustic energy. For future exploitation, composite beam design with recycled PE / rubber crumb compositions (with or without reinforcement) is feasible and depending on composition, enhanced acoustic absorption can be achieved, together with tailored mechanical properties in the composite materials and structures.

\section{Declaration of Conflicting Interests}

The author(s) declared no potential conflicts of interest with respect to the research, authorship and/or publication of this article.

\section{Funding}

The author(s) received no financial support for the research, authorship and/or publication of this article. 


\section{References}

1. Crocker MJ, Handbook of Noise and Vibration Control (John Wiley, New York, 2007).

2. Zhou H, Li B, Huang G and He J. A novel composite sound absorber with recycled rubber particles, J. Sound and Vibration 2007; 304: 400-406.

3. Zhao J, Wang XM, Chang JM, Yao Y and Cui Q. Sound insulation property of wood-waste tire rubber composite. Compos Sci Technol 2010; 70: 2033-2038.

4. Asdrubali F. Green and sustainable materials for noise control in buildings, Proc $19^{\text {th }}$ Intnl Congress on Acoustics, Madrid, Spain, 2007.

5. Fatima $S$ and Mohanty AR. Acoustical and fire-retardant properties of jute composite materials. Applied Acoustics 2011; 72: 108-114.

6. Ersoy $\mathrm{S}$ and Kucuk $\mathrm{H}$. Investigation of industrial tea-leaf-fibre waste material for its sound absorption properties. Applied Acoustics 2009; 70: 215-220.

7. Murugan D, Varughese $S$ and Swaminathan T. Recycled polyolefin-based plastic wastes for sound absorption. Polym Plast Technol Eng 2006; 45: 885-888.

8. Pfretzschner $\mathrm{J}$ and Rodriguez RM. Acoustic properties of rubber crumbs. Polym Testing 1999; 18: 81-92.

9. Swift MJ, Bris $\mathrm{P}$ and Horoshenkov KV. Acoustic absorption in re-cycled rubber granulate. Applied Acoustics 1999; 57: 203-212.

10. Asdrubali F, Baldinelli G, D'Alessandro F, Schiavoni S, Kenny JM and Iannoni A. Manufacturing process optimization of resilient materials made from recycled tyre granules. Proc $16^{\text {th }}$ Intnl Congress on Sound and Vibration, Krakow, Poland, 2009.

11. Asdrubali F, D'Alessandro F and Schiavoni S. Sound absorbing properties of materials made of rubber crumbs. J Acoustical Soc America 2008; 123: 3037-3047.

12. Aylon E, Murillo R, Fernandez-Colino A, Aranda A, Garcia T, Callen MS and Mastral AM. Emissions from the combustion of gas-phase products at tyre pyrolysis. $J$ Analytical \& Applied Pyrolysis 2007; 79: 210-214.

13. Sobral M, Samagaio AJB, Ferreira JMF and Labrincha JA. Mechanical and acoustical characteristics of bound rubber granulate. J Mat Proc Technol 2003; 142: 427-433.

14. Sunthonpagasit $N$ and Duffey MR. Scrap tire to crumb rubber: feasibility analysis for processing facilities. Resources, Conservation and Recycling 2004; 40: 281-299.

15. Rubber Manufacturers Association. Scrap tire markets in the United States. $9^{\text {th }}$ Biennial Report, 2009.

16. Horoshenkov KV and Swift MJ. The effect of consolidation on the acoustic properties of loose rubber granulates. Applied Acoustics 2001; 62: 665-690.

17. Voronina VV and Horoshenkov KV. Acoustic properties of unconsolidated granular mixes. Applied Acoustics 2004; 65:673-691. 
18. Delany ME and Bazley EN. Acoustical properties of fibrous absorbent materials. Applied Acoustics 1970; 3: 105-116.

19. Lee FC and Chen WH. Acoustic transmission analysis of multi-layer absorbers. J Sound \& Vibration 2001; 248: 621-634.

20. Heng RBW. Acoustic absorption properties of materials. Construction \& Building Mater 1988; 2: 85-91.

21. Cox TJ and D'Antonio P. Acoustic Absorbers and Diffusers: Theory, Design and Application $2^{\text {nd }} E d$. Taylor \& Francis, Oxford, 2009.

22. Wang $\mathrm{CN}$ and Torng $\mathrm{JH}$. Experimental study of the absorption characteristics of some porous fibrous materials. Applied Acoustics 2001; 62: 447-459.

23. Asdrubali F, Baldinelli $G$ and D'Alessandro F. Evaluation of the acoustic properties of materials made from recycled tyre granules. Proc 36th Intnl Congress on Noise Control Engineering. Istanbul, Turkey, 2007.

24. Brown JS. Connection between formation factor for electrical resistivity and fluid-solid coupling factors in Biot's equations for acoustic waves in fluid-filled porous media.

Geophysics 1980: 45: 1269-1275.

25. Anon. Making the connection - particle size, size distribution and rheology. Chemie.DE Information Service GmbH (1997-2010). Available at: http://www.chemie.de/articles/e/61207/ 26. Sonnier R, Leroy E, Clerc L, Bergeret A and Lopez-Cuesta JM. Polyethylene/ground tyre rubber blends: Influence of particle morphology and oxidation on mechanical properties 2007; 26: $274-281$.

27. Billmeyer FW. Textbook of Polymer Science, 3rd Ed. John Wiley \& Sons, New York, 1984.

28. Mark JE. Polymer Data Handbook. Oxford University Press, New York, 1999.

29. Punnarak P, Tantayanon S and Tangpasuthadol V. Dynamic vulcanization of reclaimed tire rubber and high density polyethylene blends. Polym Degradation \& Stability 2006; 91 : 3456-3462.

30. Goldstein JI. Scanning Electron Microscopy and X-Ray Microanalysis, 3rd Ed., Plenum Press, New York, 2003.

31. Saville P. Optimisation of Dallenbach layers using real materials. Defence Research and Development Canada DRDC Atlantic TM 2007-012, 2007. 


\section{Figure Captions}

Figure 1 Configuration of glass ribbon (upper) and glass rods (lower image) in the mould.

Figure 2 SEM photomicrographs of raw rubber crumb (left) and dispersion in HDPE matrix (see scale bars for magnification).

Figure 3 Particle size distribution data (Coulter technique) for rubber crumb.

Figure 4 Thermal analysis data for HDPE compounds containing variable rubber crumb concentrations: (a) cooling scan and (b) second heating scan.

Figure 5 Flexural stress-strain data and determinations of secant modulus (at 1\% strain) for injection moulded HDPE / rubber crumb compounds (0-20\% rubber).

Figure 6 Effect of rubber crumb weight content on flexural properties (the HDPE 'control' sample is taken as a reference).

Figure 7 Effect of rubber crumb content on the notched impact strength of recycled HDPE / rubber composites (0-20\% rubber).

Figure 8 SEM backscatter photomicrographs of cryogenically-fractured surfaces of PE I rubber crumb composites (see scale bar for magnification):

(a) Recycled HDPE (reference); (b) $10 \%$ (c) $15 \%$ and (d) $20 \%$ rubber compounds.

Figure 9 SEM-EDX phase analysis for (a) rubber particle surface, and (b) continuous polyethylene phase in the composites.

Figure 10 Flexural stress-strain curves and determination of secant modulus (at 1\% strain) for compression moulded samples 1 to 5 : effects of rubber crumb concentration.

Figure11 Flexural stress-strain curves and determination of secant modulus (at 1\% strain) for compression moulded samples 6, 12-15; effects of rubber crumb concentration.

Figure 12 Cross section images of glass reinforced compression moulded beams: (a) glass ribbon reinforced (sample 7); (b) glass rod reinforced (sample 8).

Figure 13 Comparison of flexural modulus for group 1 (samples 1 to 5), group 2 (samples 6, 12-15), group 3 (samples 16, 7, 17), group 4 (samples 8-10) and group 5 (sample 11).

Figure 14 Amplitude-frequency spectra obtained from acoustic tests for sound transmission through different compression moulded beams (sample numbers - see Table IV): (a) HDPE control; (b) HDPE + 10\% rubber; (c) HDPE $+20 \%$ rubber. 
Figure 15 Amplitude-frequency spectra obtained from acoustic tests for sound transmission through different compression moulded beams:

(a) sample 12 (uniform depth profile); (b) sample 13 (thicker centre layer of rubber crumb); (c) sample 15 (asymmetric concentration gradient).

Figure 16 Amplitude-frequency spectra obtained from acoustic tests for sound transmission through different compression moulded beams:

(a) sample 10 ( $0 \%$ rubber and $8.7 \mathrm{~mm}$ diameter glass rod);

(b) sample 17 (0\% rubber and glass ribbons, 3-layers).

(Note the different ordinate scale, in Figure 16 b).

\section{Table Captions}

Table I Formulations Used for Compression Moulded Composite Beam Samples.

Samples 6, 12-15 contain concentration gradients and are labelled with nominal concentrations of rubber crumb (\%), in the layered structures.

Table II Weight and Atomic Content of Elements in Selected Area of Rubber Crumb.

Table III Coulter laser diffraction data for Rubber Crumb.

Table IV Acoustic Properties of Compression Moulded Composite Beam Samples. 


\section{Figures and Captions}

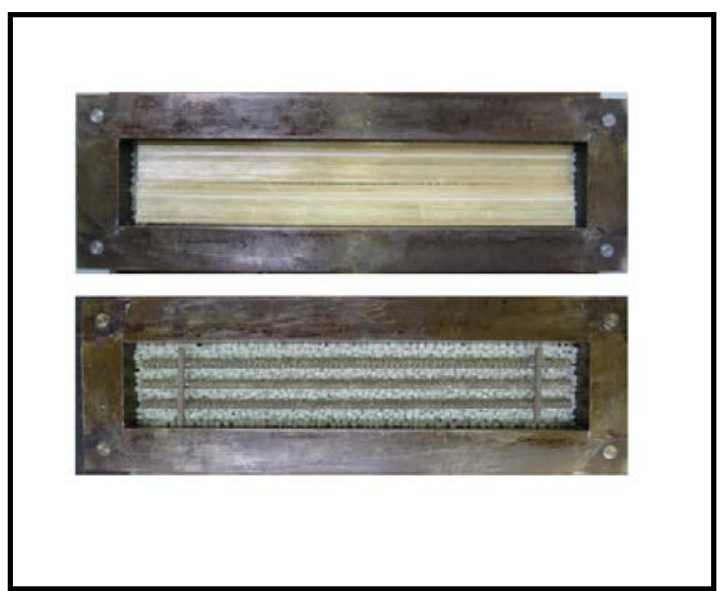

Figure 1 Configuration of glass ribbon (upper) and glass rods (lower image) in the mould.
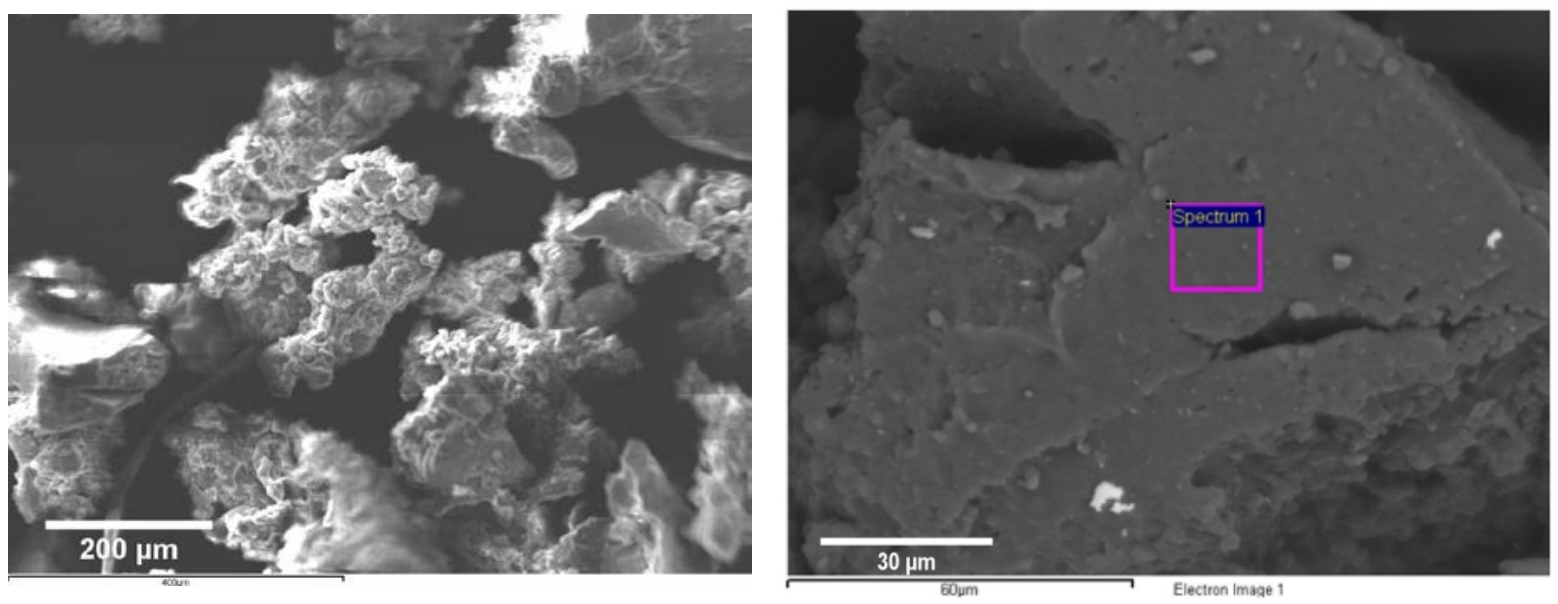

Figure 2 SEM photomicrographs of raw rubber crumb (left) and dispersion in HDPE matrix (see scale bars for magnification).

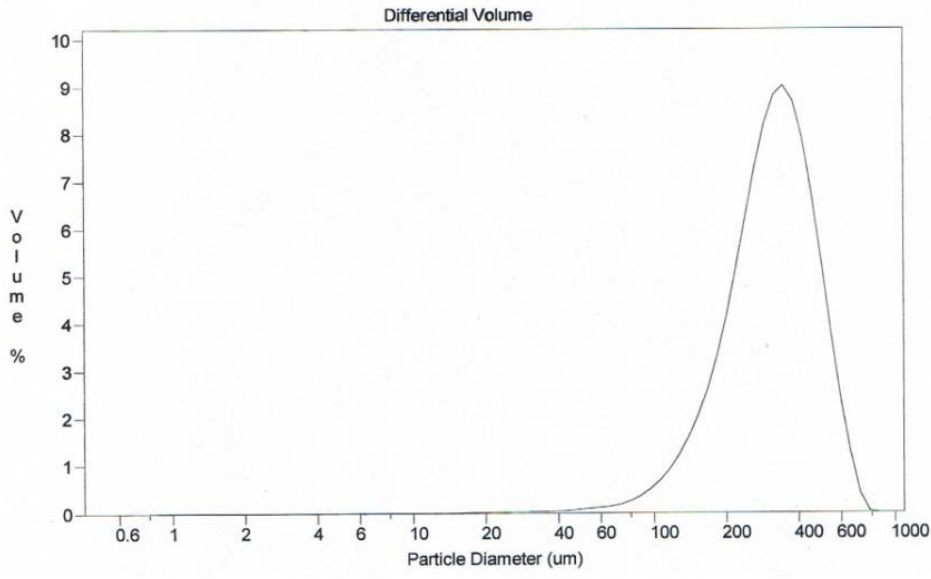

Figure 3 Particle size distribution data (Coulter technique) for rubber crumb. 


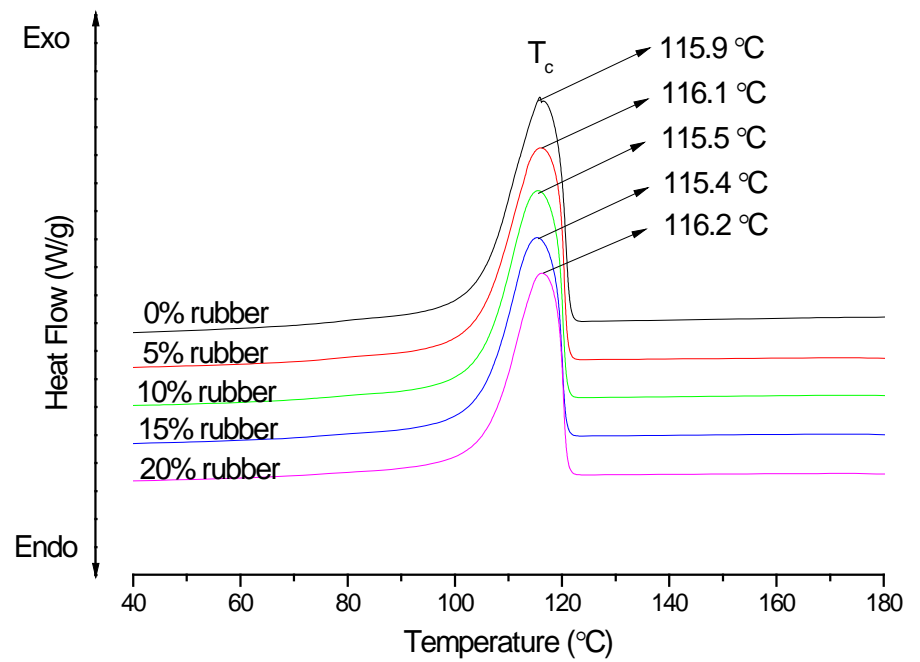

(a)

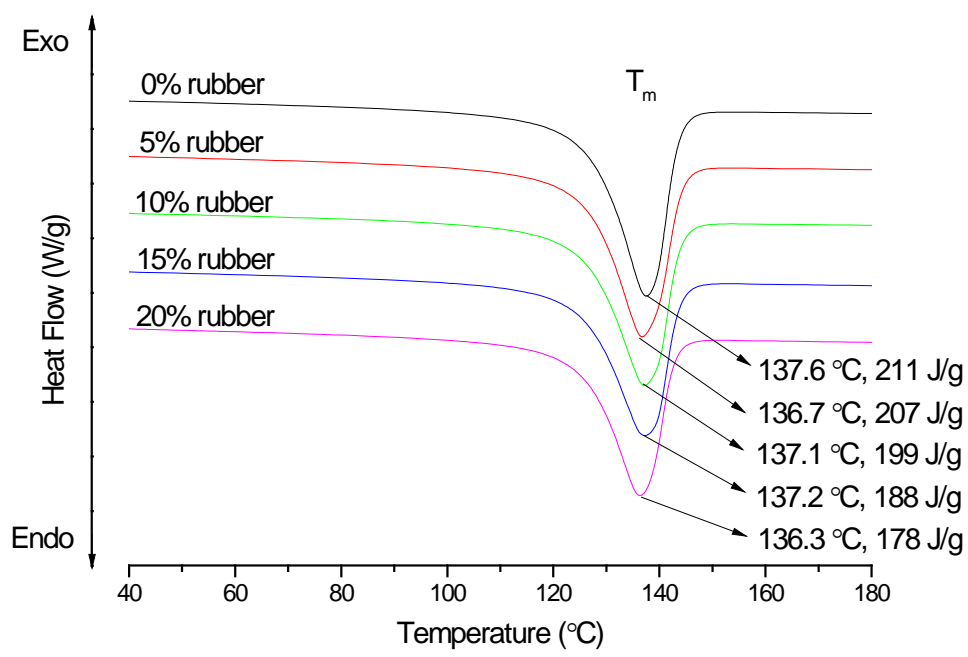

(b)

Figure 4 Thermal analysis data for HDPE compounds containing variable rubber crumb concentrations: (a) cooling scan and (b) second heating scan. 


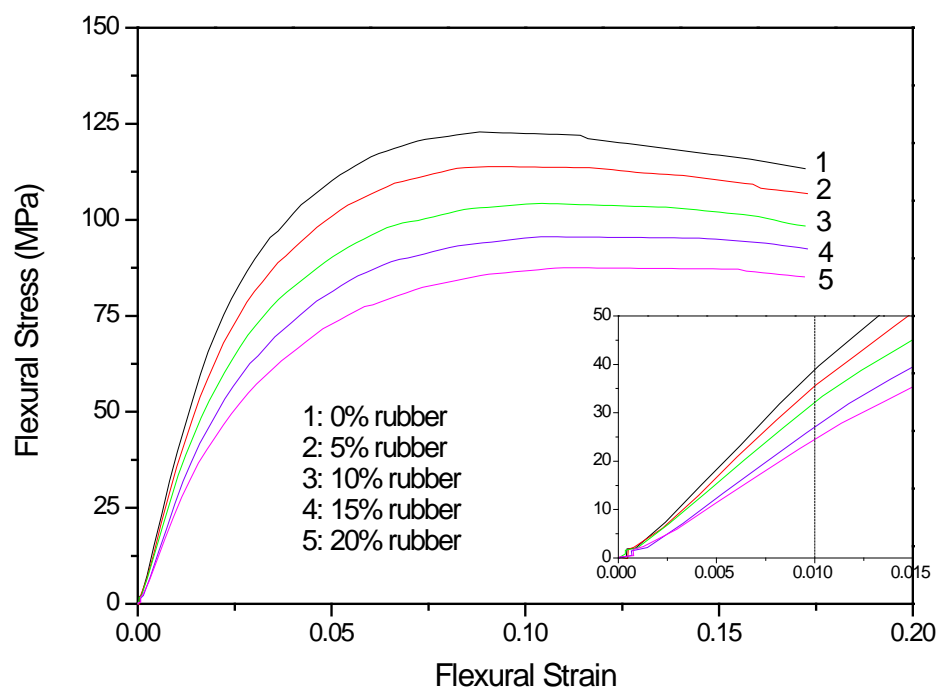

Figure 5 Flexural stress-strain data and determinations of secant modulus (at 1\% strain) for injection moulded HDPE / rubber crumb compounds (0-20\% rubber).

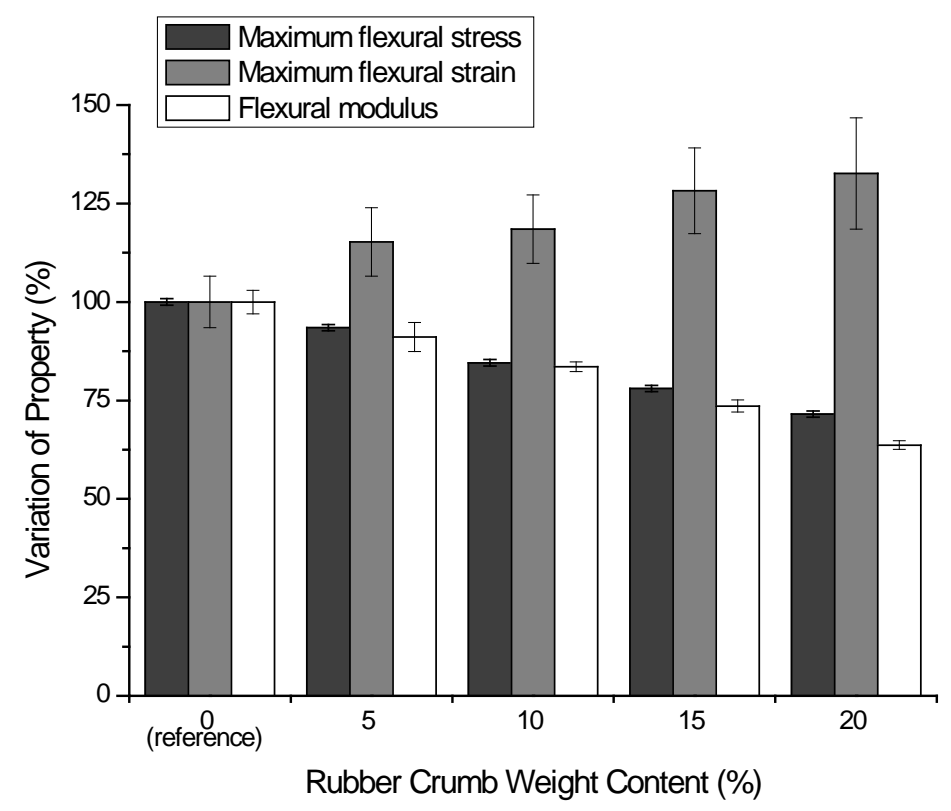

Figure 6 Effect of rubber crumb weight content on flexural properties (the HDPE 'control' sample is taken as a reference). 


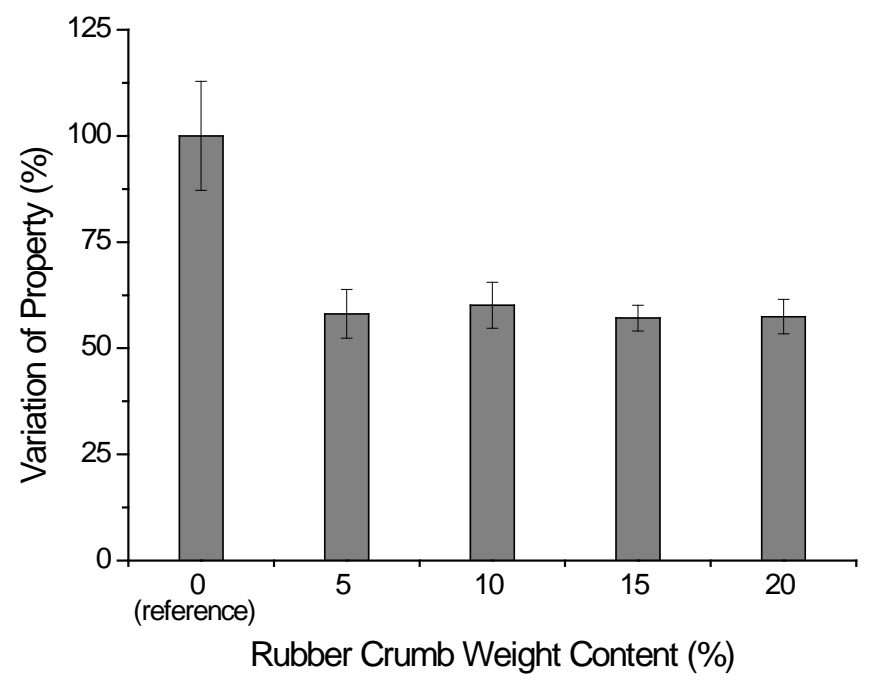

Figure 7 Effect of rubber crumb content on the notched impact strength of recycled HDPE / rubber composites (0-20\% rubber). 


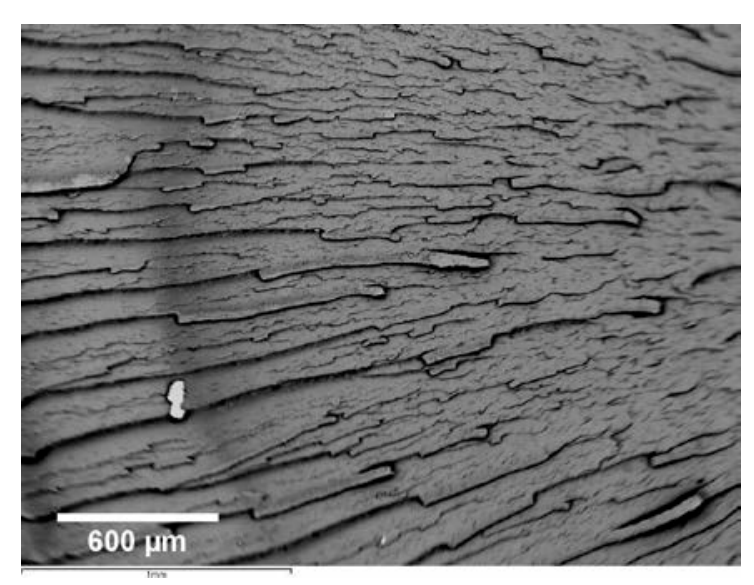

(a)

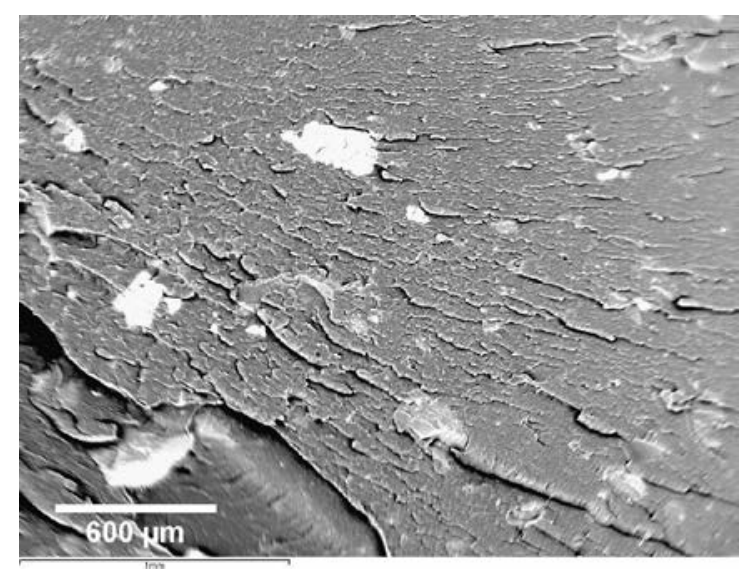

(c)

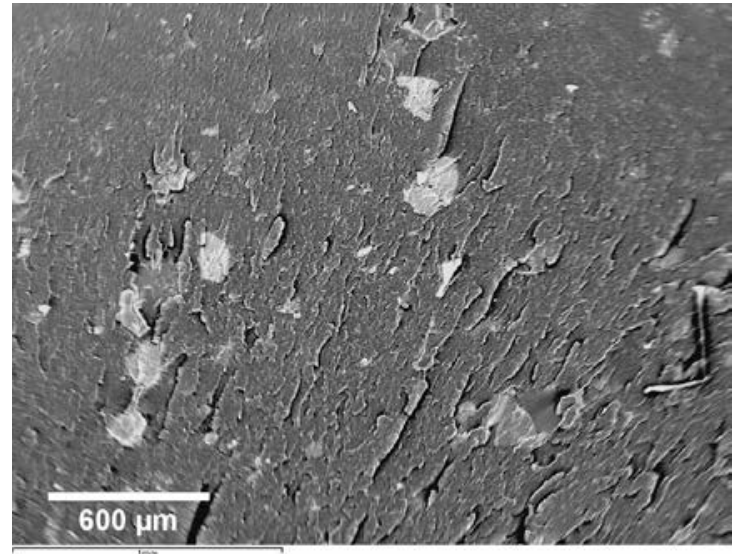

(b)

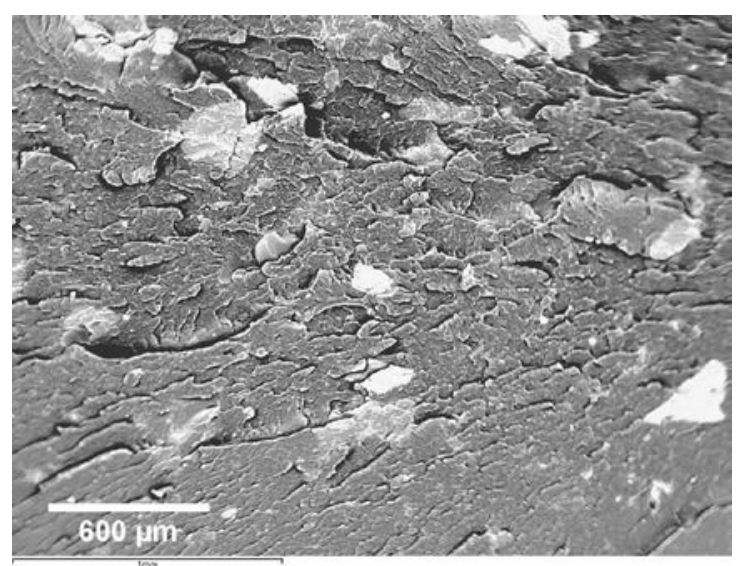

(d)

Figure 8 SEM backscatter photomicrographs of cryogenically-fractured surfaces of PE / rubber crumb composites (see scale bar for magnification):

(a) Recycled HDPE (reference); (b) 10\% (c) 15\% and (d) 20\% rubber compounds. 

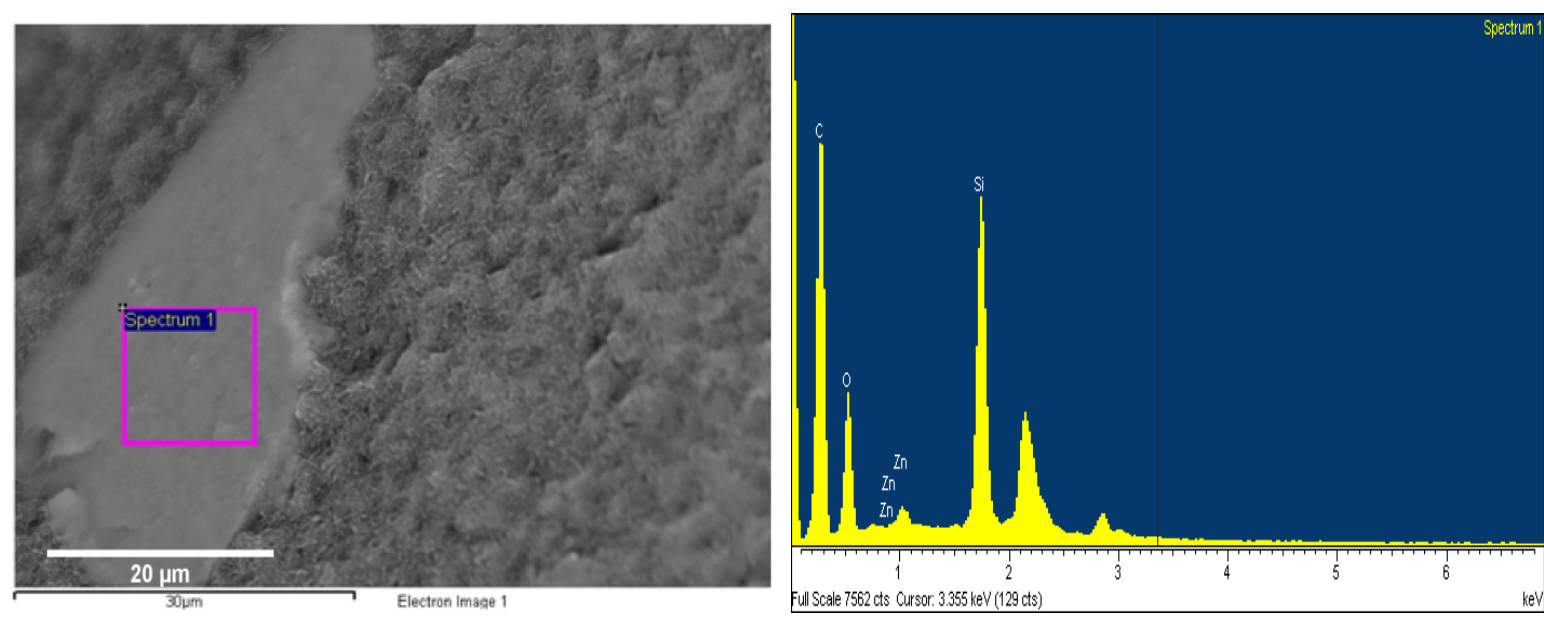

(a)
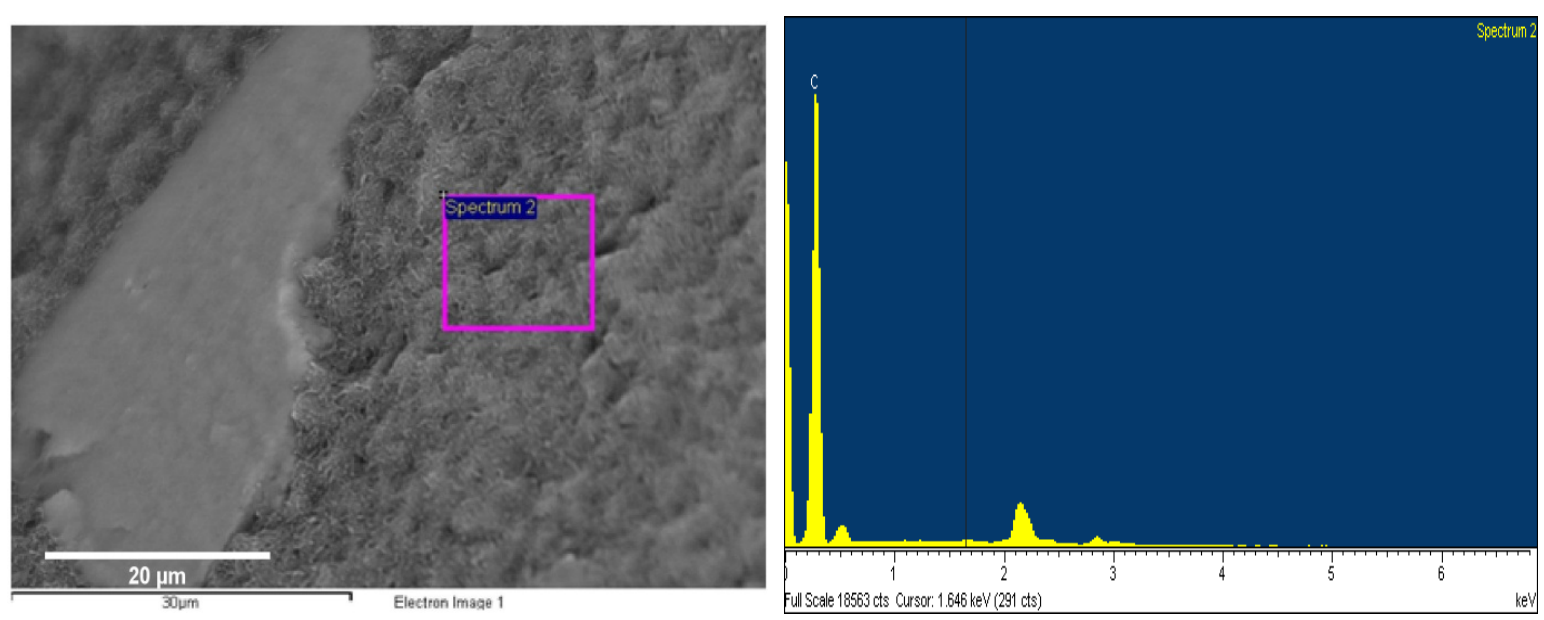

(b)

Figure 9 SEM-EDX phase analysis for (a) rubber particle surface, and

(b) continuous polyethylene phase in the composites. 


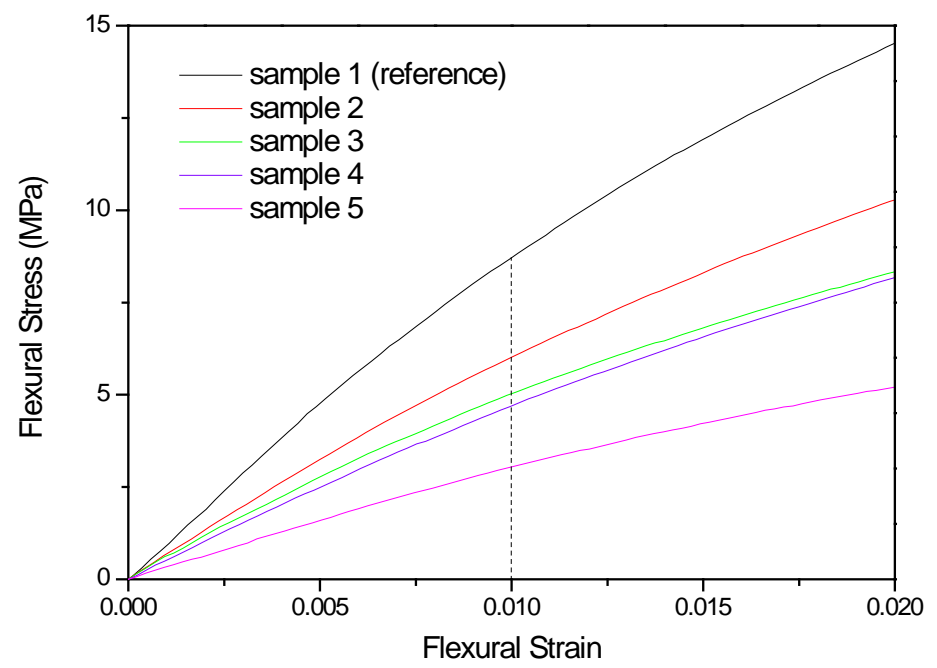

Figure 10 Flexural stress-strain curves and determination of secant modulus (at 1\% strain) for compression moulded samples 1 to 5 : effects of rubber crumb concentration.

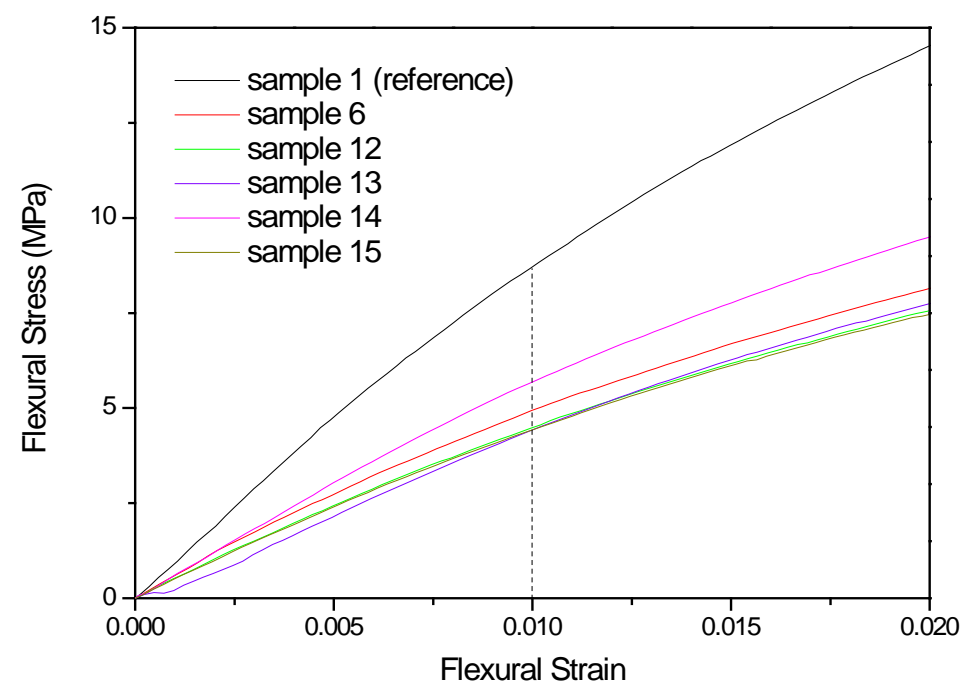

Figure11 Flexural stress-strain curves and determination of secant modulus (at 1\% strain) for compression moulded samples 6, 12-15; effects of rubber crumb concentration. 

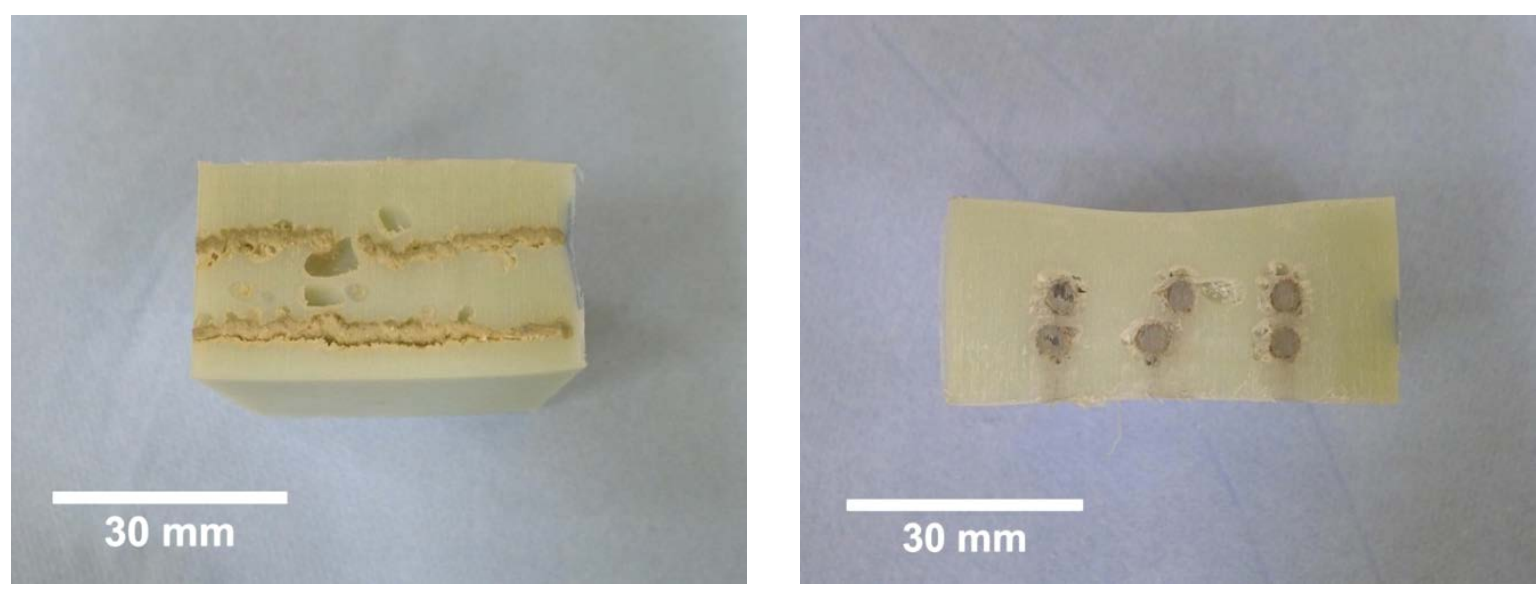

Figure 12 Cross section images of glass reinforced compression moulded beams: (a) glass ribbon reinforced (sample 7); (b) glass rod reinforced (sample 8).

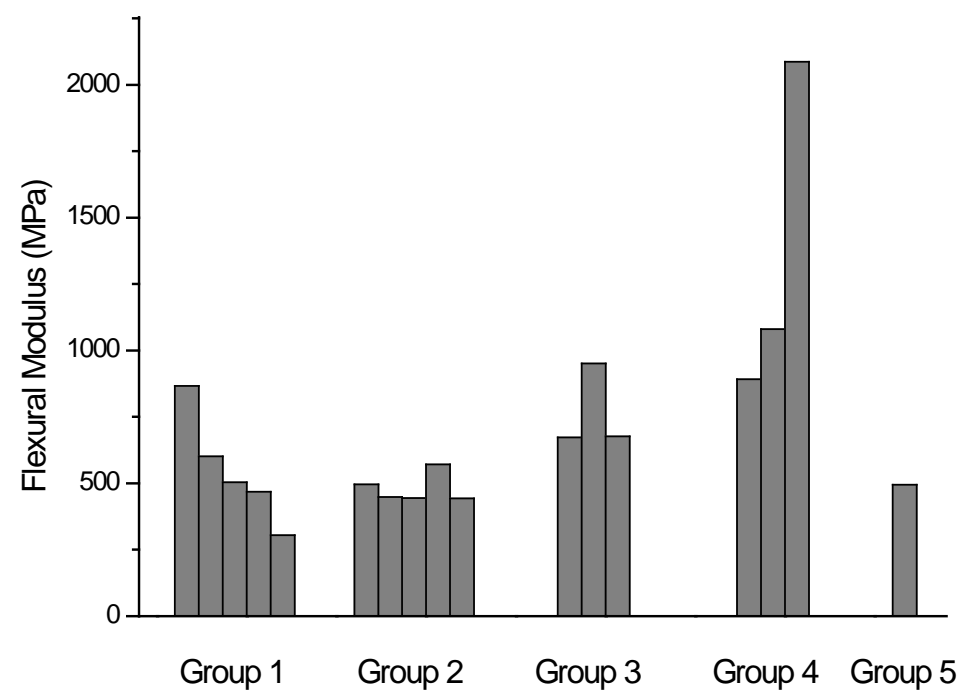

Figure 13 Comparison of flexural modulus for group 1 (samples 1 to 5), group 2 (samples $6,12-15$ ), group 3 (samples 16, 7, 17), group 4 (samples 8-10) and group 5 (sample 11). 


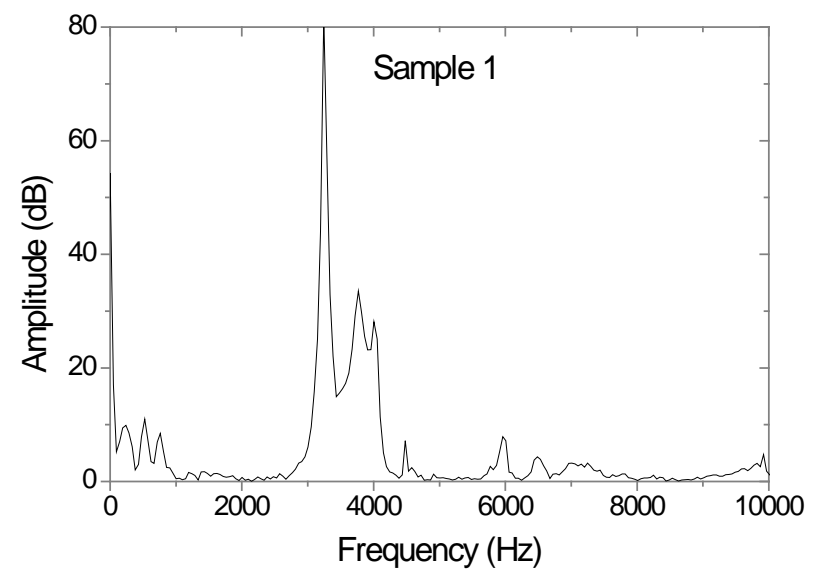

(a)

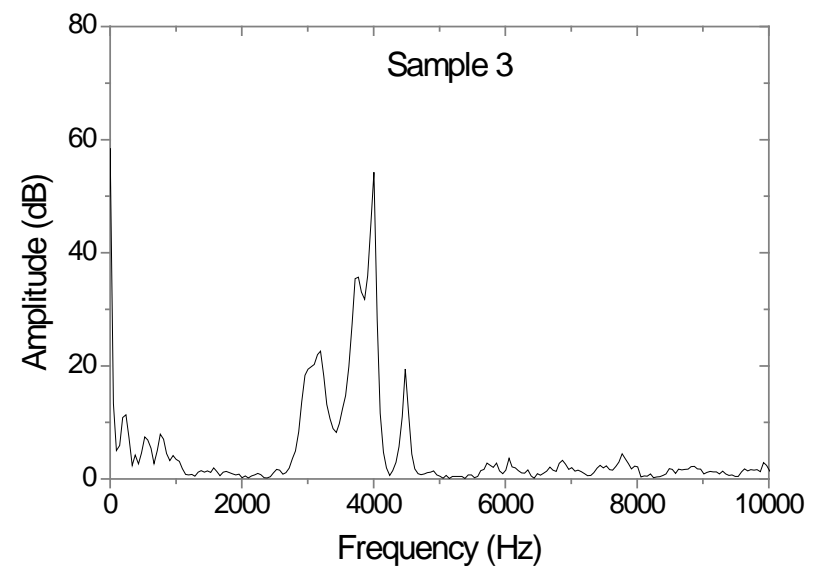

(b)

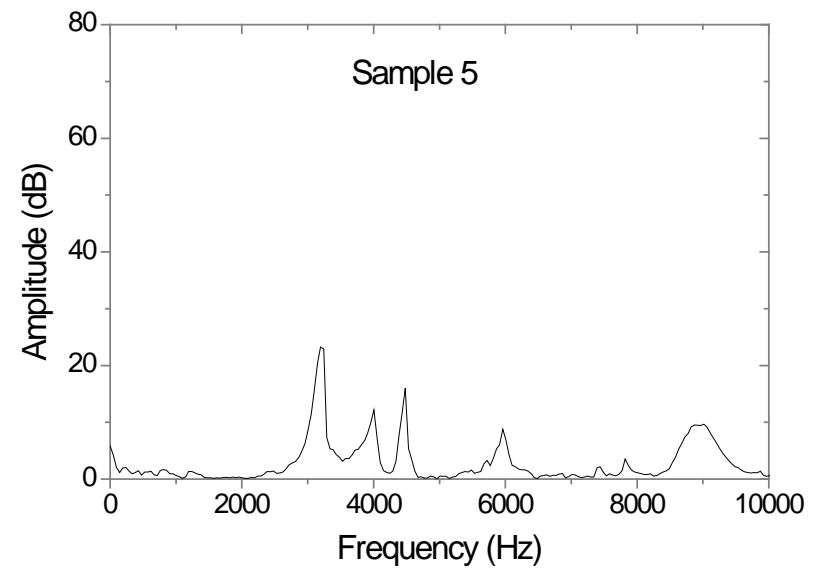

(c)

Figure 14 Amplitude-frequency spectra obtained from acoustic tests for sound transmission through different compression moulded beams (sample numbers - see Table IV): (a) HDPE control; (b) HDPE + 10\% rubber; (c) HDPE + $20 \%$ rubber. 


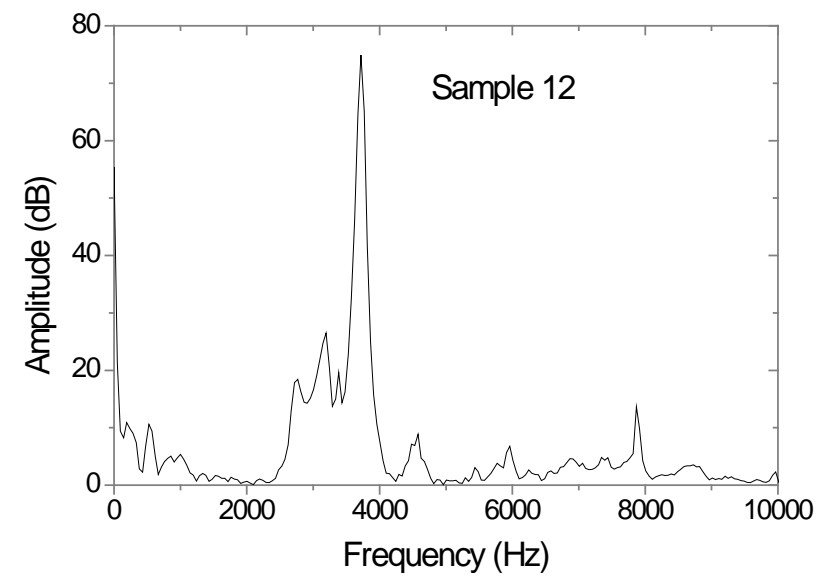

(a)

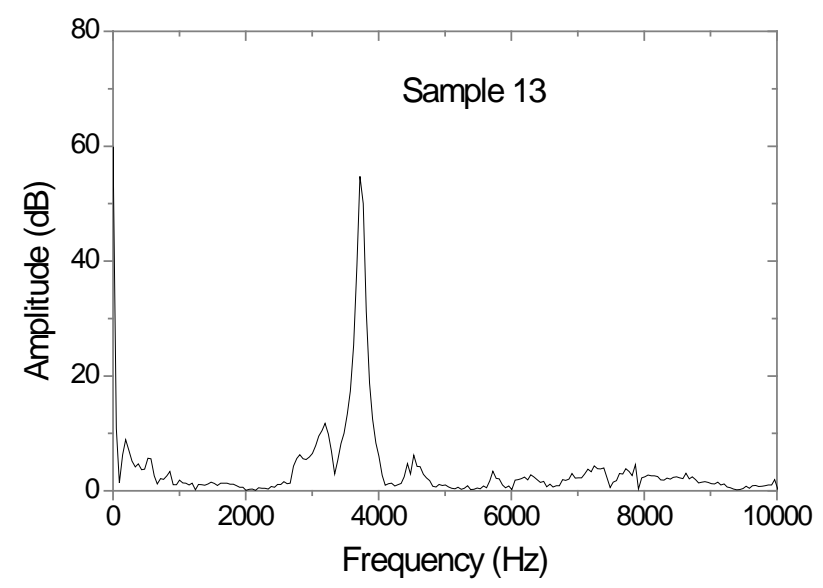

(b)

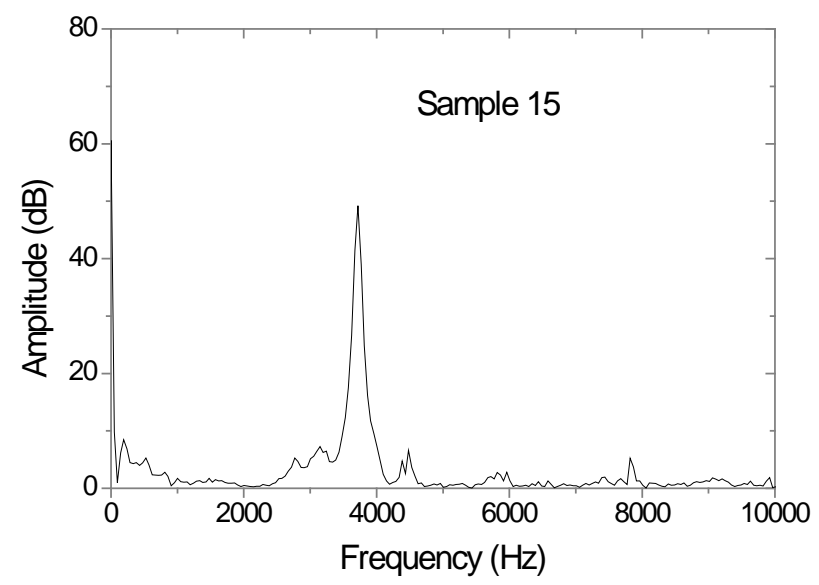

(c)

Figure 15 Amplitude-frequency spectra obtained from acoustic tests for sound transmission through different compression moulded beams:

(a) sample 12 (uniform depth profile); (b) sample 13 (thicker centre layer of rubber crumb); (c) sample 15 (asymmetric concentration gradient). 


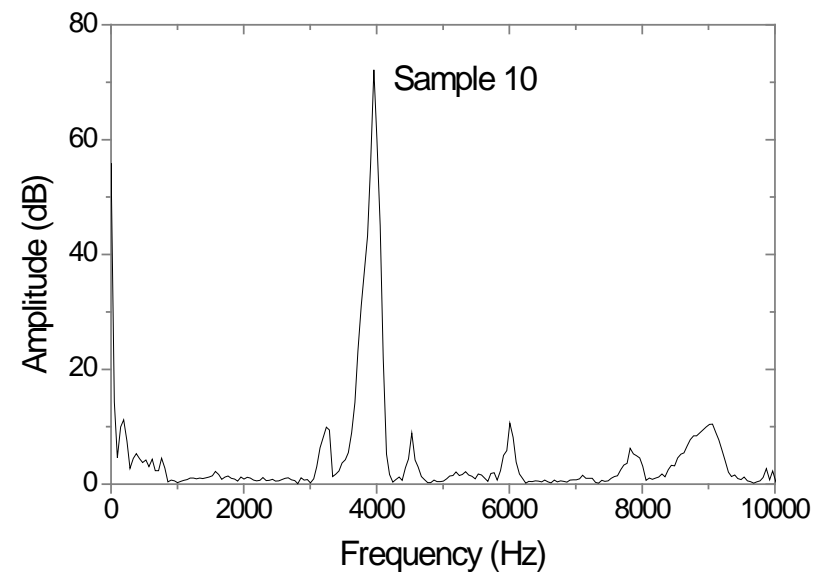

(a)

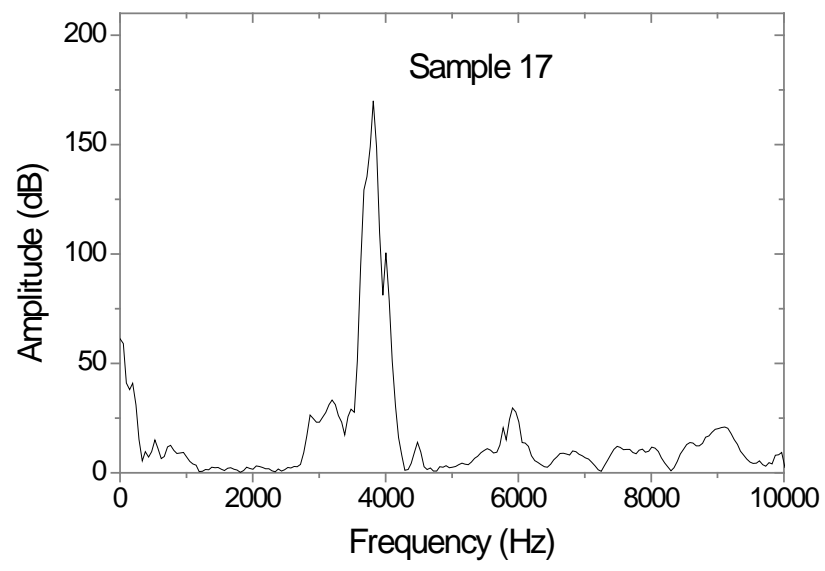

(b)

Figure 16 Amplitude-frequency spectra obtained from acoustic tests for sound transmission through different compression moulded beams:

(a) sample 10 ( $0 \%$ rubber and $8.7 \mathrm{~mm}$ diameter glass rod);

(b) sample 17 (0\% rubber and glass ribbons, 3-layers).

(Note the different ordinate scale, in Figure 16 b). 


\section{Tables}

\begin{tabular}{|c|c|}
\hline \multicolumn{2}{|c|}{$\begin{array}{l}\text { Table I } \quad \text { Formulations Used for Compression Moulded Composite Beam Samples. } \\
\text { Samples 6, 12-15 contain concentration gradients and are labelled with nominal } \\
\text { concentrations of rubber crumb (\%), in the layered structures. }\end{array}$} \\
\hline Sample & Ingredient \\
\hline 1 & 0\% rubber compound (i.e. recycled HDPE) \\
\hline 2 & $5 \%$ rubber compound \\
\hline 3 & $10 \%$ rubber compound \\
\hline 4 & $15 \%$ rubber compound \\
\hline 5 & $20 \%$ rubber compound \\
\hline 6 & $\begin{array}{l}20 / 15 \text { / } 10 / 15 \text { / } 20 \\
\text { (5 layers in percent rubber with even depth) }\end{array}$ \\
\hline 7 & $\begin{array}{l}\text { recycled HDPE + } 2 \text { layers of glass ribbons* } \\
\text { (ribbon length: } 308 \mathrm{~mm} \text {, width: } 29 \mathrm{~mm} \text {, depth: } 1.2 \mathrm{~mm} \text { ) }\end{array}$ \\
\hline 8 & $\begin{array}{l}\text { recycled HDPE + } 2 \text { layers of glass rods } \\
\text { (rod length: } 308 \mathrm{~mm} \text {, diameter: } 4.8 \mathrm{~mm} \text { ) }\end{array}$ \\
\hline 9 & $\begin{array}{l}\text { recycled HDPE + } 2 \text { layers of glass rods } \\
\text { (rod length: } 308 \mathrm{~mm} \text {, diameter: } 6.5 \mathrm{~mm} \text { ) }\end{array}$ \\
\hline 10 & $\begin{array}{l}\text { recycled HDPE + } 2 \text { layers of glass rods } \\
\text { (rod length: } 308 \mathrm{~mm} \text {, diameter: } 8.7 \mathrm{~mm} \text { ) }\end{array}$ \\
\hline 11 & $\begin{array}{l}\text { 10\% rubber compound + } 2 \text { layers of glass ribbons } \\
\text { (ribbon length: } 308 \mathrm{~mm} \text {, width: } 29 \mathrm{~mm} \text {, depth: } 1.2 \mathrm{~mm} \text { ) }\end{array}$ \\
\hline 12 & $\begin{array}{l}10 / 15 / 20 / 15 / 10 \\
\text { (5 layers of rubber crumb (\%) with even depth) }\end{array}$ \\
\hline 13 & $\begin{array}{l}10 / 15 \text { / } 20 \text { / } 15 \text { / } 10 \\
\text { ( } 5 \text { layers of rubber crumb; the } 20 \% \text { layer was } 50 \% \text { thicker) }\end{array}$ \\
\hline 14 & $\begin{array}{l}5 / 10 \text { / } 20 \text { / } 10 \text { / } 5 \\
\text { (5 layers of rubber crumb (\%) with even depth) }\end{array}$ \\
\hline 15 & $\begin{array}{l}5 / 10 \text { / } 15 \text { / } 20 \\
\text { (4 layers of rubber crumb (\%) with even depth) }\end{array}$ \\
\hline 16 & $\begin{array}{l}\text { recycled HDPE + } 1 \text { layer of glass ribbons } \\
\text { (ribbon length: } 308 \mathrm{~mm} \text {, width: } 29 \mathrm{~mm} \text {, depth: } 1.2 \mathrm{~mm} \text { ) }\end{array}$ \\
\hline 17 & $\begin{array}{l}\text { recycled HDPE + } 3 \text { layers of glass ribbons } \\
\text { (ribbon length: } 308 \mathrm{~mm} \text {, width: } 29 \mathrm{~mm} \text {, depth: } 1.2 \mathrm{~mm} \text { ) }\end{array}$ \\
\hline
\end{tabular}


* 2 layers of glass ribbons and glass rods were placed approximately $5 \mathrm{~mm}$ below the top and above the bottom surfaces of the sample.

** 1 layer of glass ribbons was placed in the middle of the sample depth.

*** 3 layers of glass ribbons were placed based on above two positions.

Table II Weight and Atomic Content of Elements in Selected Area of Rubber Crumb.

\begin{tabular}{ccc}
\hline Element & Weight, \% & Atomic, \% \\
\hline C & 82.7 & 90.8 \\
O & 8.02 & 6.62 \\
S & 2.07 & 0.85 \\
Zn & 6.34 & 1.28 \\
Si & 0.89 & 0.42 \\
\hline
\end{tabular}

Table III Coulter laser diffraction data for Rubber Crumb.

\begin{tabular}{lccccc}
\hline \multicolumn{5}{c}{ Particle Size $(\mu \mathrm{m})$} \\
\hline Mean & $\%>10$ & $\%>25$ & $\%>50$ & $\%>75$ & $\%>90$ \\
326.7 & 503.6 & 410.3 & 316.2 & 233.7 & 167.5 \\
& & & & \\
\hline
\end{tabular}


Table IV Acoustic Properties of Compression Moulded Composite Beam Samples.

\begin{tabular}{|c|c|}
\hline Sample \& description & $\begin{array}{l}\text { Transmitted sound intensity level in } \\
\text { the } 2-6 \mathrm{kHz} \text { range }\left(\mathrm{dB} . \mathrm{Hz} \times 10^{3}\right)\end{array}$ \\
\hline 1. $0 \%$ rubber (HDPE reference) & 34.4 \\
\hline 2. $5 \%$ rubber & 33.9 \\
\hline 3. $10 \%$ rubber & 34.1 \\
\hline 4. $15 \%$ rubber & 37.1 \\
\hline 5. $20 \%$ rubber & 16.5 \\
\hline 6. $20 / 15 / 10 / 15 / 20$ (even depth) & 22.7 \\
\hline 7. $0 \%$ rubber + glass ribbons (2 layers) & 27.7 \\
\hline 8. $0 \%$ rubber + glass rods (Diameter, $\mathrm{D}=4.8 \mathrm{~mm}$ ) & 29.8 \\
\hline 9. $0 \%$ rubber + glass rods (Diameter, $\mathrm{D}=6.5 \mathrm{~mm}$ ) & 34.3 \\
\hline 10. $0 \%$ rubber + glass rods (Diameter, $\mathrm{D}=8.7 \mathrm{~mm}$ ) & 27.0 \\
\hline 11. $10 \%$ rubber + glass ribbons (2 layers) & 22.2 \\
\hline 12. $10 / 15 / 20 / 15 / 10$ (even depth) & 40.7 \\
\hline 13. $10 / 15 / 20 / 15 / 10$ (50\% thicker for the $20 \%$ layer $)$ & 22.6 \\
\hline 14. 5/10/20/10/5 (even depth) & 32.5 \\
\hline 15. 5/10/15/20 (even depth) & 20.1 \\
\hline 16. $0 \%$ rubber + glass ribbons ( 1 layer) & 98.5 \\
\hline 17. $0 \%$ rubber + glass ribbons ( 3 layers) & 100.5 \\
\hline
\end{tabular}

